\title{
Author Spotlight: Joel Gabre
}

\section{Joel Gabre ${ }^{1}$}

Published online: 5 May 2020

๑) Springer Science+Business Media, LLC, part of Springer Nature 2020

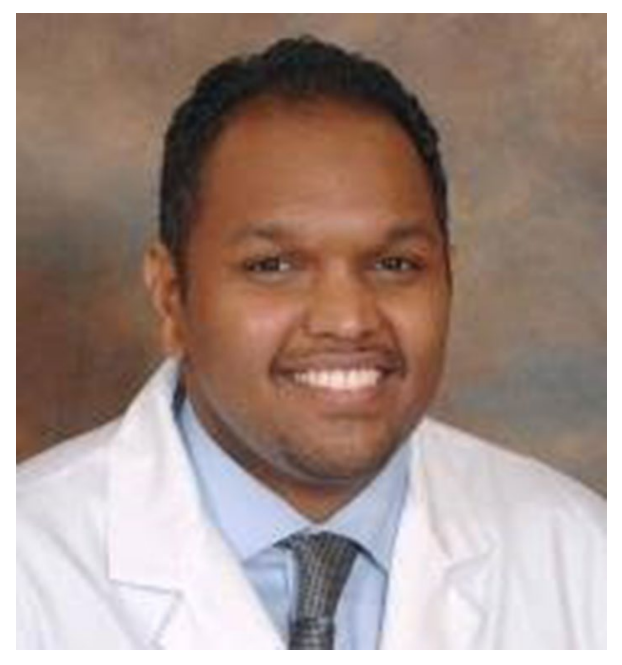

Joel Gabre, MD, is a third-year and chief gastroenterology fellow at the University of Pennsylvania. He completed his internal medical residency at the University of Cincinnati and medical degree at the University of Maryland. He is currently a T-32 postdoctoral trainee studying molecular mechanisms of Barrett's esophagus and esophageal adenocarcinoma (EAC) through the use of 3D esophageal organoids. After fellowship, he intends to pursue a career as a physician scientist focusing on esophageal cancer biology.

Publisher's Note Springer Nature remains neutral with regard to jurisdictional claims in published maps and institutional affiliations.

Joel Gabre

Joel.Gabre@pennmedicine.upenn.edu

1 Philadelphia, USA 